\title{
A simulation of Argo float distribution in the Southern Ocean
}

\author{
Tsugukazu Okumura*,***, Naoto Iwasaka*,** and Eitarou Oka**
}

\begin{abstract}
Spatial distribution of the Argo floats in the Southern Ocean was simulated based on an output of a high resolution ocean general circulation model.

Giving initial uniform distribution of the floats, numerical simulations were performed for the parking depths of $2000 \mathrm{~m}$ and $1000 \mathrm{~m}$, respectively, with and without sea ice. When the sea ice was ignored, the floats were distributed almost uniformly even four years later but generally showed northward shift. Under sea ice condition, most of the floats were lost south of $62^{\circ} \mathrm{S}$ one year after the float deployment while most of the floats survived north of $53^{\circ} \mathrm{S}$ if the sea ice concentration was considered as the survival rate of the float in the corresponding region.
\end{abstract}

Keywords: Argo float, the Southern Ocean, simulation of float distribution, sea ice

\section{Introduction}

The International Argo Project started in 2000 to build a real-time monitoring system of upper and middle layers of the world ocean using profiling floats in order for improvement of long-term weather forecasts and climate predictions. Ultimately the monitoring network will consist of about 3000 profiling floats in the world ocean with average spacing of $300 \mathrm{~km}$ under cooperation of the participating countries during the project (e.g., Mizuno, 20001); Roemmich and Owens, 2000²); Saiki, 2000 ${ }^{3)}$ ). About 1,500 Argo floats were active in the world ocean as of November 22, 2004. Although many countries such as the United States, Canada, France, India, and Japan have been deploying profiling floats in the world ocean, the Southern Ocean has been left as a float-scarce-region.

In the present study, the Argo float distribution and its time evolution in the Southern Ocean were simulated to give a basis for developing a strategy to extend the monitoring network to the Southern Ocean with minimum costs and efforts. The results of the simulation will be helpful to the design of the logistics for the deployment of the floats and to maintenance of the monitoring system. In the simulation, seasonal change in sea ice distribution around the Antarctic was considered.

\section{Method of simulation}

\subsection{Simulation of float drift}

Drift of Argo floats was simulated using the particletracking method based on velocity data of an ocean general circulation model, the same as Oka $(2001)^{4)}$ and
Okumura et al. (2004) $)^{5}$.

The simulation was made for two different parking depths; one was $2000 \mathrm{~m}$ and the other $1000 \mathrm{~m}$. The parking depth of $2000 \mathrm{~m}$ is the standard sampling depth for the international Argo project and many of the Argo floats drift at the same level of the sampling depth. Recently several float operators have employed so called the "park and profile" maneuver of the Argo float. That is, the parking depth is shallower than the sampling depth and the float dives down to the sampling depth just before making observation. In order to simulate the drift of the "park and profile" type floats, we performed a simulation for the parking depth of $1000 \mathrm{~m}$.

Product of a high-resolution ocean general circulation model (OGCM) run by JAMSTEC was used for the simulation. The horizontal velocity output was stored every five days during the last year of the seasonal variability experiment of the model run. This output was used as the seasonal velocity data for the float drift simulation. The velocity data at Level 1 (top layer at 5-m depth) and at Level 43 (2045 m), which were closest to the sea surface and the parking depth of $2000 \mathrm{~m}$, respectively, were used. The velocity data at Level 32 (1007 $\mathrm{m})$ was also used for the simulation for the parking depth of $1000 \mathrm{~m}$. The time step of the simulation corresponded to two hours.

The Argo floats which the JAMSTEC is currently operating in the ocean have the observational cycle of ten days, including the period at the sea surface for about 11 hours. Correspondingly, the particle-tracking computation was made on the condition that particles

\footnotetext{
* Tokyo University of Marine Science and Technology, Faculty of Marine Technology Etchujima

** Institute of Observational Research for Global Change

*** Present affiliation: East Japan Railway Company
} 


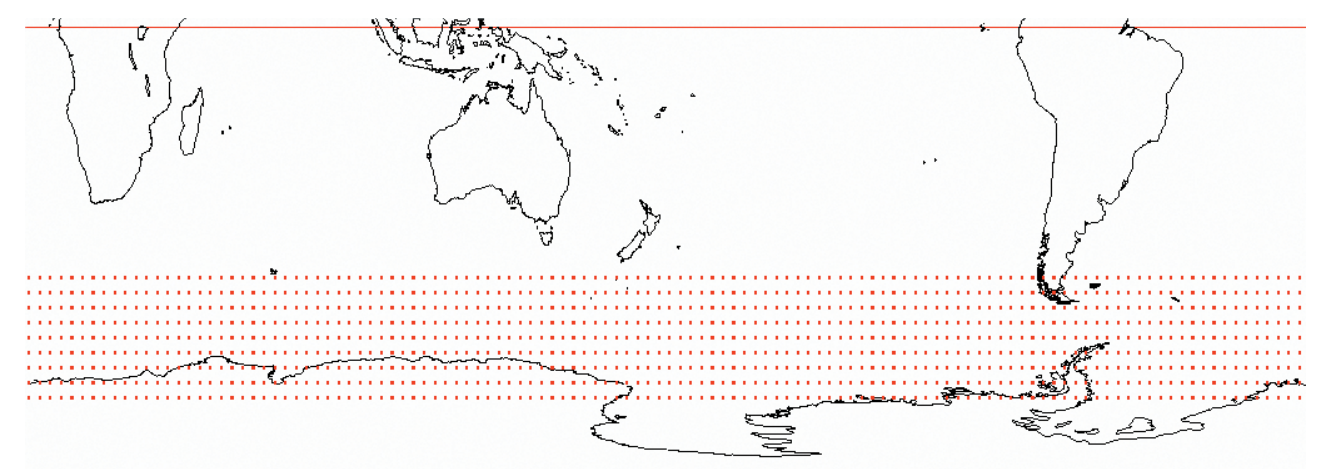

Figure 1: Initial positions of particles for 4-year-long simulation of the float movement. Red squares are the initial positions for the simulations for the parking depth of $2000 \mathrm{~m}$ and $1000 \mathrm{~m} .25$ particles are uniformly distributed in each red square of $0.5^{\circ}$ by $0.5^{\circ}$. The red squares are equally spaced both longitudinal and latitudinal direction by $3^{\circ}$, from $50^{\circ} \mathrm{S}$ to $74^{\circ} \mathrm{S}$ around the Antarctica. Since the particles on the lands did not moved during the simulation, the authors would like to ask the readers to ignore them in the figure.
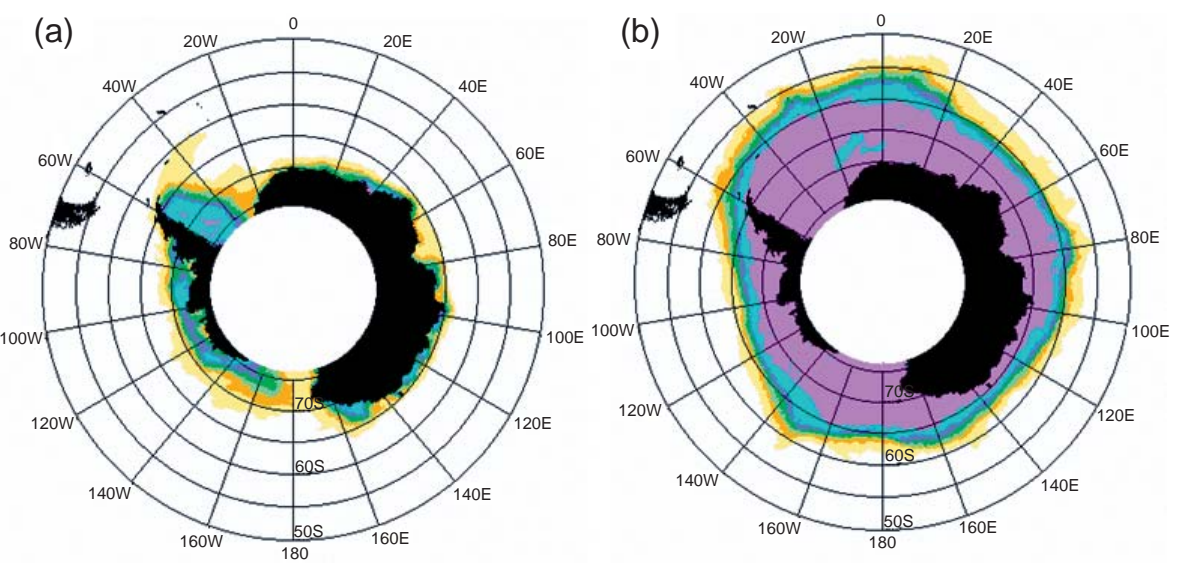

Figure 2: Climatological mean sea ice extent around the Antarctic Continent. Left figure (a) shows that for 60th day (early March) and the right (b) for 230th day (late September) of the year, respectively. The climatology was computed by Okumura et al. (2004).

stayed alternately at Level 43 (about $2000 \mathrm{~m}$ depth) or Level 33 (about $1000 \mathrm{~m}$ depth) for 114 time steps (9 days and 12 hours) and at Level 1 for 6 steps (12 hours). The time of ascent and descent of the floats, which is about six hours each, were ignored in the simulation.

All the particles repeated same observation cycle in exact timing for four years. Differences between current fields on the last day of a year and those on the first day of the next year in the simulation may be larger than those expected from natural oceanic changes because one-year-long velocity fields of the 20th year OGCM run was used repeatedly four times for the four-year simulation. We, however, ignored the possible discontinuity in the model current fields. When the floats touched the bottom, the position and the date were recorded.

In case that a float entered the region shallower than the parking depth during its surface drifting and touched the sea bottom during the following descent, the float was supposed not to move at the sea bottom for about nine days until it started rising up again. Correspondingly, when a particle was found in the region shallower than the parking level just before its descent, it was assumed that the particle did not move horizontally at the parking level for the following 114 time steps and then started moving again at Level 1.

At the beginning of the simulations, 25 particles were uniformly distributed in a $0.5^{\circ}$ latitude by $0.5^{\circ}$ longitude square and the square was placed every $3^{\circ}$ longitude and $3^{\circ}$ latitude between $50^{\circ} \mathrm{S}$ and $74^{\circ} \mathrm{N}$ (Fig. 1). We initially located the particles uniformly in the latitude belt because of the simplicity of the initial condition of the simulation. Since the particles on the lands did not moved during the simulation, the authors would like to ask the readers to ignore them in the figures. 

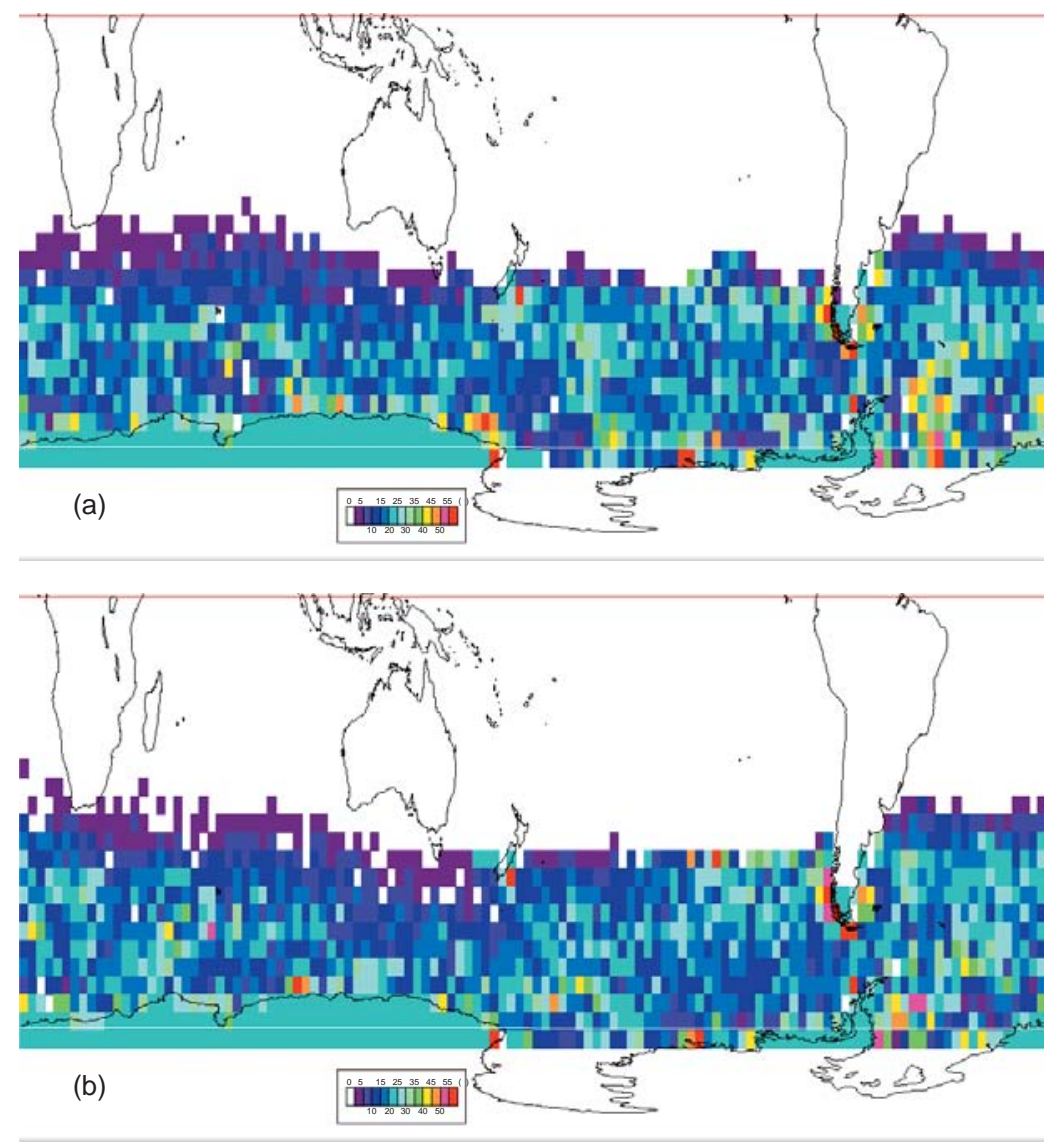

Figure 3: Geographical distributions of the particles at the end of the fourth year without sea ice effect, (a) for the parking depth of $2000 \mathrm{~m}$ and (b) for $1000 \mathrm{~m}$. The particle density is computed for every $3^{\circ}$ longitude by $3^{\circ}$ latitude square and $9^{\circ}$ longitude by $9^{\circ}$ latitude spatial running mean was applied to smooth out some small scale variability. The color scale indicates the particle density every 5 counts par $3^{\circ}$-squared region from $0^{\circ}$ through $60^{\circ}$. As mentioned before, ignore the results on the lands.

\subsection{Simulation of sea ice effect}

A self-consistent way to simulate sea ice effect on the Argo float distribution in the Southern Ocean should be the simulation using an ocean-atmosphere-sea-ice coupled model. Unfortunately there are no reliable coupled models, so far, which can be used for the simulation. Thus, in the present study, the float distribution was first simulated without sea ice information for four years. The simulation period corresponds to the designed life time of the Argo float. Then a climatological sea ice distribution dataset was used to estimate the effect of sea ice on survival rate of the Argo floats. It was not assumed that existence of sea ice affected the float movement at the sea surface.

"1972-1994 Arctic and Antarctic Sea Ice Data", which was compiled and distributed by the National Ice Center (NIC), the United States of America, was used to compute a climatological mean seasonal sea ice distribution and its evolution around the Antarctic. The original NIC dataset, in which the weekly mean was given for every calendar week, was processed to form 7-day mean dataset computed for every 7-day period beginning from January 1 st every year by Okumura et al. $(2003)^{6)}$. The last one or two days of each year were ignored in the process. Based upon the processed dataset, 5-day mean, $0.25^{\circ}$ by $0.25^{\circ}$ grid average sea ice climatology was computed by applying a linear interpolation. The sea ice distribution was given for the area north of $75^{\circ} \mathrm{S}$ because of the limitation of the ocean model domain. Maximum and minimum extent of sea ice distributions around the Antarctic Continent are shown in Fig. 2.

Sea ice concentration, which is the ratio of sea ice area to total area of the interested grid, was considered as survival rate of the Argo float in the simulation. When a particle ascended into the grid of which the sea ice concentration was larger than zero, a random number was generated and compared it to the rate. When the random number was smaller than the rate, the particle was treated as being lost. In other words, we assumed 
Table 1: Float lost rate (\%) every 3 months after the float deployment on January 1st. Indicated latitude is the middle of each $3^{\circ}$ latitude belt.

\begin{tabular}{|c|c|c|c|c|c|c|c|c|c|c|c|c|}
\hline & \multicolumn{4}{|c|}{ Indian Sector $\left(20^{\circ} \mathrm{E}-120^{\circ} \mathrm{E}\right)$} & \multicolumn{3}{c|}{ Pacific Sector $\left(120^{\circ} \mathrm{E}-180^{\circ}-72^{\circ} \mathrm{W}\right)$} & \multicolumn{4}{c|}{ Atlantic Sector $\left(72^{\circ} \mathrm{W}-0^{\circ}-20^{\circ} \mathrm{E}\right)$} \\
\hline Latitude & 3months & 6months & 9months & 12 months & 3months & 6months & 9months & 12 months & 3months & 6 months & 9 months & $12 \mathrm{months}$ \\
\hline $50^{\circ} \mathrm{S}$ & 0 & 0 & 0 & 0 & 0 & 0 & 0 & 0 & 0 & 0 & 0 & 1 \\
\hline $53^{\circ} \mathrm{S}$ & 0 & 0 & 6 & 7 & 0 & 0 & 0 & 0 & 0 & 1 & 12 & 19 \\
\hline $56^{\circ} \mathrm{S}$ & 0 & 0 & 22 & 30 & 0 & 0 & 2 & 3 & 0 & 7 & 67 & 70 \\
\hline $59^{\circ} \mathrm{S}$ & 2 & 15 & 87 & 90 & 0 & 4 & 15 & 17 & 23 & 47 & 86 & 86 \\
\hline $62^{\circ} \mathrm{S}$ & 12 & 93 & 98 & 98 & 1 & 28 & 62 & 64 & 64 & 90 & 93 & 93 \\
\hline $65^{\circ} \mathrm{S}$ & 98 & 99 & 99 & 99 & 54 & 89 & 99 & 100 & 87 & 92 & 92 & 92 \\
\hline $68^{\circ} \mathrm{S}$ & 100 & 100 & 100 & 100 & 98 & 100 & 100 & 100 & 100 & 100 & 100 & 100 \\
\hline $71^{\circ} \mathrm{S}$ & 100 & 100 & 100 & 100 & 100 & 100 & 100 & 100 & 100 & 100 & 100 & 100 \\
\hline $74^{\circ} \mathrm{S}$ & 100 & 100 & 100 & 100 & 100 & 100 & 100 & 100 & 100 & 100 & 100 & 100 \\
\hline
\end{tabular}

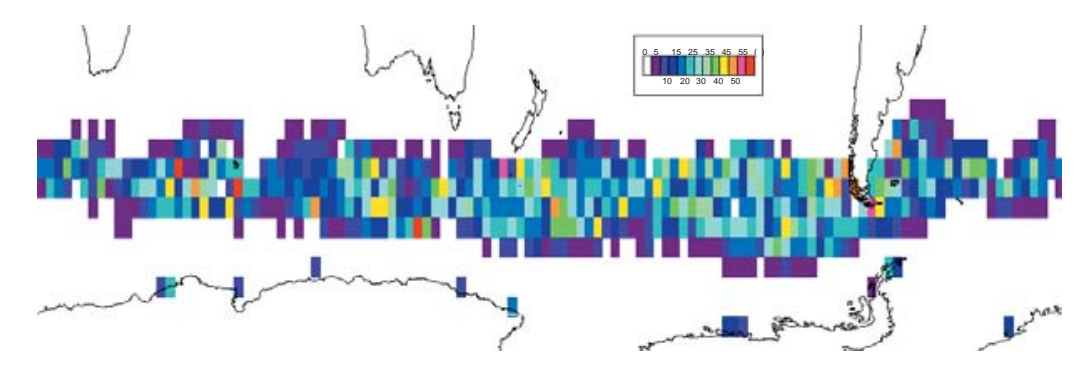

Figure 4: The same as Figure 3, except for particle distribution one year after the deployment for the case that the simulation started on January 1st. The parking depth was $2000 \mathrm{~m}$.

that the floats would be broken when they surfaced into the sea ice clusters. This is because the Argo float has an antenna and a conductivity-temperature sensor on the top of the body which are not considered to withstand the collision with the sea ice when the float rises up to the sea surface. In fact, most of the floats deployed in high latitudes of the Antarctic Ocean were lost during the sea ice extent season.

\section{Results}

Figure 3a shows geographical distributions of the particles at the end of the fourth year for the parking depth of $2000 \mathrm{~m}$, without sea ice effect. Fig. 3b is the same as Fig. 3a, except for the parking depth of $1000 \mathrm{~m}$.

The particles are almost uniformly distributed but slightly shifted to the north. There are several particles convergence regions such as to the east of the Antarctic Peninsula, where many particles experienced bottom touching during the simulations. There were no significant differences in the particle distribution between the parking depth of $2000 \mathrm{~m}$ and that of $1000 \mathrm{~m}$.

Most of the particles were drifted eastward in entire simulation region except for coastal areas of the Antarctic Continent. Average movement of the particles in $50^{\circ} \mathrm{S}-60^{\circ} \mathrm{S}$ latitudes was $2230 \mathrm{~km}$ and that in $60^{\circ} \mathrm{S}$ - $70^{\circ} \mathrm{S}$ was $1760 \mathrm{~km}$ during the simulation period.

Many of the particles experienced bottom touching in the coastal area of the Antarctic Continent, south of New Zealand, the Antarctic Peninsula and several islands in the Southern Ocean. Initial positions of the particles that experienced bottom touching were along the coastal areas and to the west of the bottom touching regions, as expected from the average movement of the floats.

Float distributions under sea ice condition were examined. Because most of the particles in the sea ice region were lost after the first sea-ice season (Table 1), we will present here the results of the first year of the simulation period. Table 1 shows the rate of lost floats every 3 months for the simulation started on January 1st. 6 months later, Most of the particles had been lost south of $65^{\circ} \mathrm{S}$ in the Pacific and Atlantic sectors while it took only 3 months for the most particles to be lost south of $62^{\circ} \mathrm{S}$ in the Indian Ocean. In both cases, most of the floats survived for one year in the regions north of $53^{\circ} \mathrm{S}$ in the Atlantic Ocean, north of $56^{\circ} \mathrm{S}$ in the Indian Ocean and north of $59^{\circ} \mathrm{S}$ in the Pacific Ocean, respectively. Figure 4 shows the float distribution one year after the initial state the under sea ice condition. 


\section{Discussion}

As mentioned in the section 2, the simulation method of sea ice effects on the float distributions in the Southern Ocean in the present study does not exactly reproduce natural process happened in the ocean but the results of the simulation were reasonably acceptable although some floats actually survives for more than one year south of $65^{\circ} \mathrm{S}$, according to Argo Information Center (http://w3.jcommops.org/cgibin/WebObjects/Argo.woa/438/wo/).

When one plans to deploy the floats in high latitudes in the Southern Ocean, it is desirable that the float has the capability to return into deep water before crashing into sea ice or to sleep in the deep water when the sea surface is covered with sea ice. This can be achieved by programming the maneuver prior to the deployment or by controlling the maneuver through satellite communication between the float operator and the float. Such maneuvering requires slightly more intelligent floats and two way data transmitting satellite systems.

In order to continue observation under the sea ice by profiling floats, underwater positioning system is necessary to utilize the data obtained under sea ice. For such observation, the float must has the capability to memory all the observed and position data under the sea ice for at least 6 months and to transmit the data to the land station at the first rise after the underwater observation period. The positioning and satellite data transmit systems are, however, not expected to be available near future. They should be considered in the post ARGO project.

\section{References}

1) Mizuno, K., "A plan of the establishment of Advanced Ocean Observation System (Japan ARGO)" (in Japanese), Techno Marine, 854, 485-490 (2000).

2) Roemmich, D. and W. B. Owens, "The Argo project: global ocean observations for understanding and prediction of climate variability", Oceanography, 13, 45-50 (2000).

3) Saiki, M., "ARGO project" (in Japanese), Kishou, 44(7), 4-8 (2000).

4) Oka, E., "A simulation for deployment of ARGO floats", JAMSTECR, 44, 9-16, (2001)

5) Okumura., T., N. Iwasaka, E. Oka, and K.Takeuchi, "A simulation of Argo float distribution in the South Pacific", JAMSTECR, 49, 43-50, (2004).

6) Okumura, T., A. Futamura, N. Iwasaka and K. Otsuka, "Study on the distribution of the sea ice over the Sea of Okhotsk and the Bering Sea", Journal of Japan Institute of Navigation, 108, 85-96, (2003). (In Japanese with English abstract and figure captions).

(Received December 16, 2004) 